\title{
Detecting Human Papillomavirus Type 16 in Cervical Cancer Patients with Molecular Variation of Gene L1 in Riau Province Indonesia
}

\author{
Maya Savira ${ }^{1,2 *}$, Donel $\mathbf{S}^{3}$, Andani Eka Putra ${ }^{4}$, Yusrawati Yusrawati, \\ Nur Indrawati Lipoeto ${ }^{6}$
}

\begin{abstract}
Background: Cervical cancer is the second most deadly cancer in the world after breast cancer. The cancer is caused by infection of high risk Human Papillomavirus (HPV) type 16. It is often found in cervical cancer of which the genome structure is composed of L1 proteins. The L1 protein makes up the viral capsid that has an important role in causing the cervical epithelium. Several studies have found the differences in HPV nucleotides variants that lead to changes in amino acids that disrupt the structure, the natural function of the virus itself, and ultimately lead to changes in biological functions including host immunological recognition. Variation of the L1 gene also affects the effectiveness of existing vaccines. Methods: This research was a descriptive study conducted at the laboratory of microbiology, the Faculty of Medicine, Universitas Riau, Pekanbaru from February to August 2018. The study was aimed at looking at the molecular variations of the L1 HPV type 16 gene and examining phylogenic kinship. Results: The SNPs (Single Nucleotide Polymorphism) which occurred in 26 sample isolates are the substitution of C/G (6240), A/G (6432), T/G (6686), C/T (6824). These variations also cause changes in amino acids, insertion of ATC nucleotide bases (6902), and deletions of GAT bases (6954). Conclusion: There are molecular variations of the L1 HPV type 16 gene which can cause different host immune responses. Phylogenic kinship of HPV type 16 isolate in Riau is similar to Asian-American isolate.
\end{abstract}

Keywords: Cervical cancer- type 16 HPV- L1 gene HPV- molecular variation

Asian Pac J Cancer Prev, 23 (1), 87-92

\section{Introduction}

Cervical cancer ranks 4th for incidence and mortality rates in women around the world (Bray et al., 2018). Cervical cancer is the second most malignant disease of women in Indonesia (Bruni et al., 2017). Based on epidemiological data, there is a significant increase in the number of cervical cancer cases. For instance in 2012, 528,000 new cases and 266,000 deaths were estiamte (Ferlay et al., 2015), and in 2018 these figures increased to 569,847 new cases and 311,365 deaths (Bray et al., 2018). With this trend, it is estimated that by 2025 cervical cancer in the world reaches 20 million new cases (Ferlay et al., 2015). Recurrence and metastasis are still the leading causes of cervical cancer death even though cervical cancer has the ability to heal at an early stage through surgery and chemotherapy (Rezai et al., 2019).
There are many risk factors for cervical cancer and the most importatn of them is Human papillomavirus (HPV) infection (Kessler TA, 2017).

It is estimated that $5 \%$ of cancers in humans are caused by Human papillomavirus (HPV) infections, some of these cancers originate from cervical cancer. Type $16 \mathrm{HPV}$ is a major cause of cervical cancer, which is responsible for $45.5 \%$ and $60 \%$ of cancer cases worldwide and in Indonesia respectively (Bruni et al., 2017). In the case Riau province, 894 new cases of cervical cancer is expected every year (Pangribowo, 2019). Based on observations using the data in the Department of Gynaecology Oncology of Arifin Achmad Regional General Hospital, there has been an increase in the number of new cervical cancer patients in the last 4 years, including 43 new cases in 2014, 117 new cases in 2015, 113 new cases in 2016, and 219 new cases in 2017 . It is reported that $70 \%$ of cervical cancer is caused

${ }^{1}$ Faculty of Medicine, Andalas University, Padang, West Sumatera, Indonesia. ${ }^{2}$ Department of Microbiology, Faculty of Medicine, Universitas Riau, Pekanbaru, Riau, Indonesia. ${ }^{3}$ Department of Obstetry\& Gynecology, Faculty of Medicine, Universitas Riau, Arifin Achmad General Hospital, Pekanbaru, Riau, Indonesia. ${ }^{4}$ Department of Microbiology, Faculty of Medicine, Andalas University, Padang, West Sumatera, Indonesia. ${ }^{5}$ Department of Obstetry\& Gynecology, Faculty of Medicine, Andalas University, Padang, West Sumatera, Indonesia. ${ }^{6}$ Department of Clinical Nutrition, Faculty of Medicine, Andalas University, Padang, West Sumatera, Indonesia. *For Correspondence: mayadonel@yahoo.co.id 
by the infection of oncogenic type of HPV (high risk), and it is associated with anogenital cancers in men and women such as the penis, vulva, vagina, anal, and oropharyngeal cancer (Pan et al., 2019). There are 12 different types of high-risk HPV genotypes in the category of carcinogens for humans, namely genotypes 16, 18, 31, 33, 35, 39, 45, 51, 52, 56, 58, 59 (International Agency for Research on Cancer (IARC)). About $70 \%$ of cervical cancers are type 16 and 18 (Kovacevic et al., 2019).

Studies on cervical cancer samples have proven that the presence of HPV deoxyribonucleid acid (HPV DNA) in $99.7 \%$ cases dominated by types $16,18,31$ and 45 . This shows the role of high-risk HPV in the development of cervical cancer (Zouheir et al., 2016).

Human papillomavirus (HPV) is a double-stranded, non-envelope DNA viruses measuring around 7,200-8,000 base pairs. It is enveloped in a capsid protein which is composed of L1 protein (major capsules) and L2 protein (minor capsid). The viral genome is divided into three regions, namely non-coding regions (initial regulation) also known as long-control regions (LCR) of 400-1.000 bp. The second region is an initial region consisting of an Early Protein Open Reading Frame (ORF) such as E1, E2, $\mathrm{E} 4, \mathrm{E} 5, \mathrm{E} 6$, and $\mathrm{E} 7$, the third region is the region of late protein that encodes L1 and L2 proteins, which form a viral capsids or viral envelopes where L1 and L2 capsids play a role in the transmission of HPV viruses (Jing et al., 2018).

Viral genome replication is mediated directly by the E1 viral helicase and the E2 DNA-binding protein, while coordination of viral genome amplification and virulence is performed by accessory proteins E4, E5, E6, E7. The encoding of capsid proteins necessary for the final stage of virion assembly and the entry of the virus into the host cell is mediated by the L1 and L2 genes (Faraji et al., 2017).

The L1 and L2 proteins can make virus-like particles which have an effective immune response.

this has been used as an ideal target for HPV vaccines. The discovery of nucleotide differences in HPV variants lead to changes in amino acids that can interfere the structure, specific viral functional or antigenic characteristics which are considered important to distinguish potential transmission and to define epitopes that are relevant to vaccine design (Schellenbacher et al., 2017). Structural diversity presenting on the surface of L1 protein between different papillomavirus species is believed to depict the evolution of virus's mutations that are antigenic diversity (Choi and Park, 2016).

Several studies have proven that there are variations in the HPV-16 L1 gene in several countries. These L1 gene variations can affect viral binding, which in turn influences the structure or adjustment of proteins and ultimately leads to changes in biological function including host immunological recognition. This affects the effectiveness of existing vaccines. According to El aliani's study, there were 17 nucleotide chagnes in 35 samples, namely silent mutation and five missense mutations. The five missense mutations are A / C (6694), G / A (6801), G / A (6819), ATG Insertion (6903), and GAT Deletions (6950). However, none of the five missense mutations affected the L1 immunogenic region, while A/C substitution (6694) in loop H-1 showed the potential impact of mutations on the effectiveness of existing anti-HPV vaccines (El-Aliani et al., 2017).

\section{Materials and Methods}

\section{Ethics Statement}

This research was a descriptive design study with ethical approval from the ethical committee, Faculty of Medicine, Universitas Riau (089/UN.19.5.1.1.8/ UEPKK/2018). An informed written consent was signed by each participant.

\section{Sample Collection}

From February 2018 to August 2018, 110 samples of cervical tissue were collected using punch biopsy technique from cervical cancer women in Arifin Achmad Regional General Hospital, the Microbiology Laboratory of the Faculty of Medicine, Universitas Riau, Pekanbaru. The samples were taken from patients with cervical cancer based on complaints, symptoms, clinical examinations and Pap smear results. The samples from cervical tissue biopsies were extracted using the Invitrogen kit.

Out of 110 samples, 86 were positive HPV and 24 were negative HPV. Out of the 86 positive HPV samples, there were 35 sample isolates infected by HPV 16 and successfully sequenced. From 35 HPV 16 samples, only 26 samples were detected for L1 HPV 16 protein.

\section{HPV Detection with Universal Primer}

The HPV detection used DNA amplification. The $\mathrm{MY} / \mathrm{GP}$ primers used were cgtccacaagagggaatactgatc for forward and gcaccagggatcataactaatgg for reverse. The total volume of the PCR mixture was $50 \mathrm{ml}$ consisting of 0.5 to $20.0 \mathrm{ml}$ DNA, $50 \mathrm{mMTris}-\mathrm{HCl}$ (pH 8.4), $10 \mathrm{mM} \mathrm{KCl}$, $2.0 \mathrm{mM} \mathrm{MgCl}, 1 \%$ b-mercaptoethanol, $0.05 \%$ bovine serum albumin, $0.2 \mathrm{mM}$ deoxynucleoside triphosphate, 20 pmol from each primer, and $2.5 \mathrm{U}$ of Taq polymerase (Boehringer Mannheim). Amplification was done using Mini kit PCR master mix (Invitrogen) and sequencing was carried out using the primary walking method. The PCR stage was started with a temperature of $94^{\circ} \mathrm{C}$ for $5 \mathrm{~min}$, followed by 40 amplification cycles $\left(94^{\circ} \mathrm{C}\right.$ for $30 \mathrm{~s} ; 45 \mathrm{oC}$ for $60 \mathrm{~s}$; and $72^{\circ} \mathrm{C}$ for $60 \mathrm{~s}$ ) and the final stage of extension ( $72^{\circ} \mathrm{C}$ for $10 \mathrm{~min}$ ). The $450 \mathrm{bp} \mathrm{PCR}$ products were analyzed using $1 \%$ agarose gel electrophoresis.

The primer was designed for the whole HPV genome using Primer 3 Plus. Due to the large size of the virus, three pairs of primers were designed with doubling at the tip of the target region (Table 1).

To obtain nucleotide base sequence from the HPV$16 \mathrm{~L} 1$ gene, the PCR results were processed through a sequencing process. The process of analyzing the results of sequencing data was done in Bioedit (version 7.0.4.1), NCBI BLAST, and CLUSTALX. For the construction of phylogenetic trees, we used software and MEGA 6 so that phylogenetic trees were arranged. Phylogenetic trees were made based on sequences of HPV-16 and their genetic relationship through comparing the sequence of nucleotide bases from the HPV-16 L1 gene isolates of cervical cancer patients from other countries. The phylogenetic tree gene L1 HPV 16 can be seen in Figure 1. 


\section{Results}

Based on the results of the amplification using three pairs of forward and riverse primers, DNA fragments of different sizes were obtained namely primer I 718 bp, primary II $1000 \mathrm{bp}$, and primary III $751 \mathrm{bp}$ (Figure $2 \mathrm{a}, 2 \mathrm{~b}, 2 \mathrm{c})$. The sequence data of nucleotide base pairs isolates samples obtained from the sequencing results were compared to the reference sequences of the HPV-16 L1 gene in the GenBank (K02718.1). The analyses yielded a sequence size of $1596 \mathrm{bp}$. Based on sequencing analysis, it was found that all isolates sample experienced SNPs in their DNA sequences, while not all nucleotide bases matched the reference sequence HPV-16 (K02718.1).

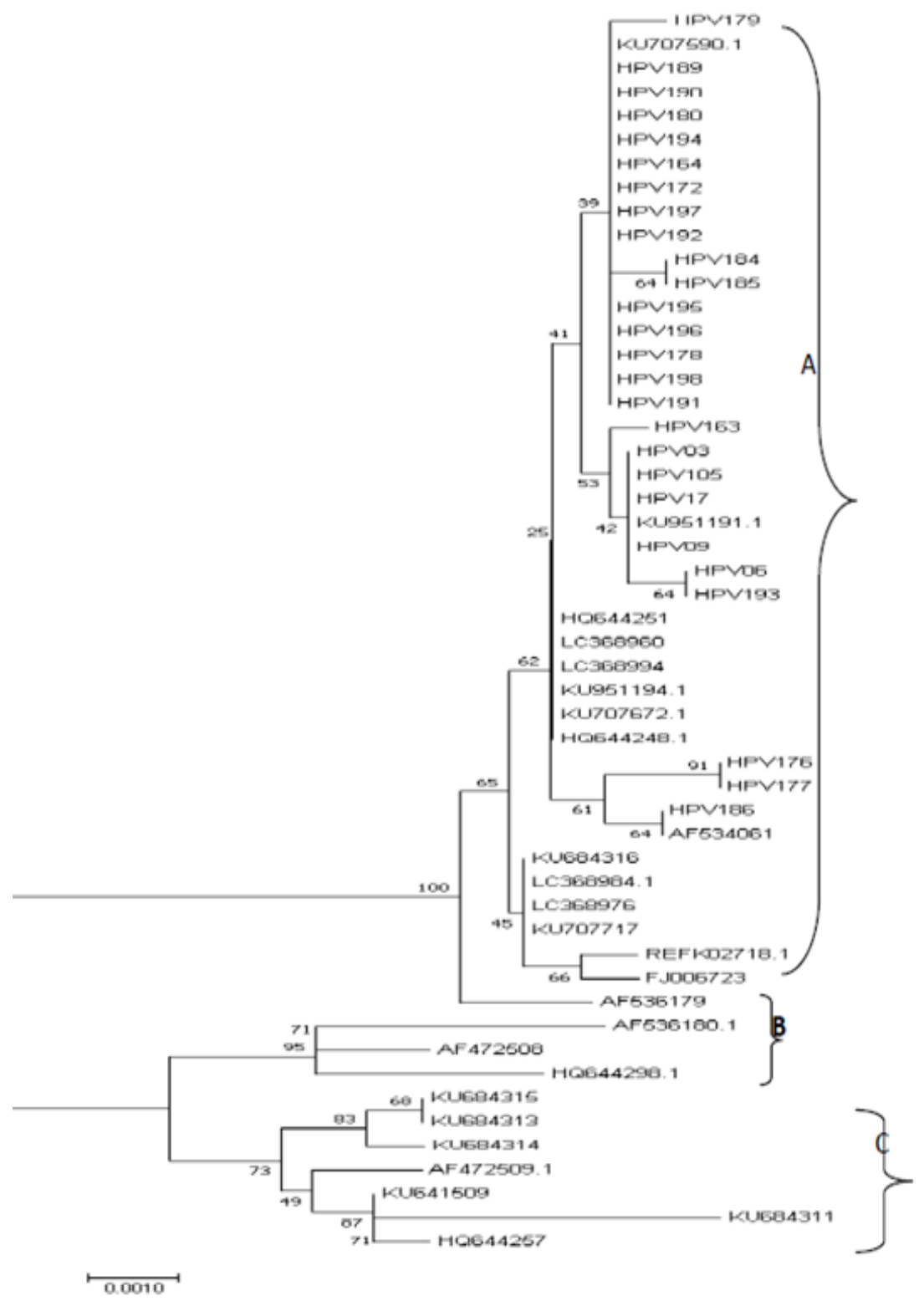

Figure 1. The Result of Phylogenic Tree Construction Based on Nucleotide Sequence of L1 Gene from 26 Isolates of HPV Type 16, Isolate Reference K02718.1, and three Other HPV Type 16 Variants Asia-America (AA), African Variant $(\mathrm{AF})$, and European Variant (E). This construction uses Neighbor-Joining method and Kimura2-parameter model contained in MEGA program $\AA$

Table 1. L1 Primary Genes of HPV-16

\begin{tabular}{lll}
\hline Primer Type & Primer Position & Primer Measurement \\
$H P V-16 L 1$ Gene specific primary I & F : AGTTCCAGGGTCTCCACAAT & $718 \mathrm{bp}$ \\
& R : TCAACCATATCACCATCCTGAA & \\
$H P V-16 L 1$ Gene specific primary II & F : CTAGTG AGG CCACTGTCTACTT & $1000 \mathrm{bp}$ \\
& R : TCCCCATGTCGTAGGTACTCCTTA & \\
$H P V-16 L 1$ Gene specific primary III & F : AACCTTATTGGTTACAACGAG & $751 \mathrm{bp}$ \\
& R : GCATGACACAATAGTTACACAAGC & \\
\hline
\end{tabular}


Table 2. The Variation of HPV-16 L1 Gene Isolate Samples Mutation

\begin{tabular}{lcccl}
\hline Mutation & Position & Total & $(\%)$ & Sample \\
\hline ACT Insertion & 6901 & $26 / 26$ & 100 & All isolate samples \\
SNPs C/G & 6240 & $26 / 26$ & 100 & All isolate samples \\
SNPs A/G & 6432 & $26 / 26$ & 100 & All isolate samples \\
SNPs T/G & 6688 & $26-\mathrm{Mar}$ & 11,5 & HPV06, 17, 193 \\
SNPs C/T & 6823 & $23 / 26$ & 88 & HPV03,06,09,17,105,164,172,178,179,180,184,18 \\
& & & & $5,186,189,190,191,192,193,194,195,196,197,198$ \\
GAT Deletion & 6953 & $26 / 26$ & 100 & All isolate samples \\
\hline
\end{tabular}

$\mathbf{a}$
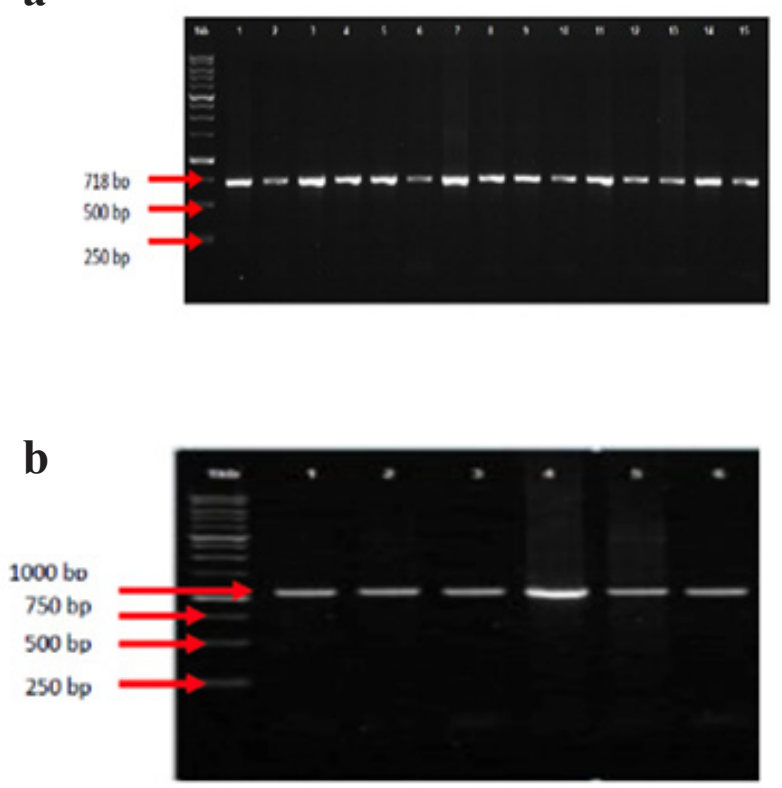

C

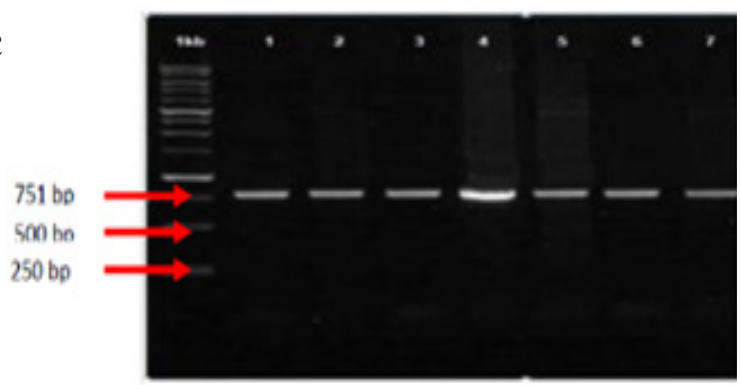

Figure 2. a, Primary Amplification I 718 BP; b, Primary Amplification II 1000 BP; c, Primary Amplification III $751 \mathrm{BP}$
These SNPs have the potential to affect the amino acid composition (Table 2). These results were processed using CLUSTALX and MEGA 6 programs. The genetic relationship was analysed by making phylogenic trees of HPV-16 L1gene using the variants from Asian-Americans (AA), Europe (E) and Africa (Af). Overall, the sample isolates had a kinship relationship with Asian-American sample isolates (Figure 1).

Based on the results of cytological examinations carried out on all samples of this study, almost all of them were squamous cell carcinomas (95\%). All samples were at stage IIB cervix cancer, stage IIA, and IIIB in a descending order (Figure 3).

\section{Discussion}

It was found that $74.3 \%$ of combined isolate samples (26 isolates out of 35 isolates of the HPV DNA) were infected by Human papillomavirus type 16 . The prevalence was reported by a research conducted in India equal to $95.6 \%$ (221 positive HPV-16 out of 231 positive samples of HPV) (Kumar N, 2016).

High-risk HPV DNA testing has a higher sensitivity than cytology examination; while, it has a lower specificity compared to persisted HPV infections or relapsed HPV infections after eradicating (Costa et al., 2015). Cervical infection by the oncogenic HPV genotype (high risk HPV) is strongly associated with the diagnosis of pre-cancerous lesions and cervical carcinoma, especially HPV 16, 18, 31, and 45 (Téllez et al., 2015).

The HPV DNA testing is more cost effective when compared to cytology examinations (Mendes et al., 2015).

The HPV type 16 is a type of HPV that often infects cervical tissue and can cause cervical cancer. The HPV-16

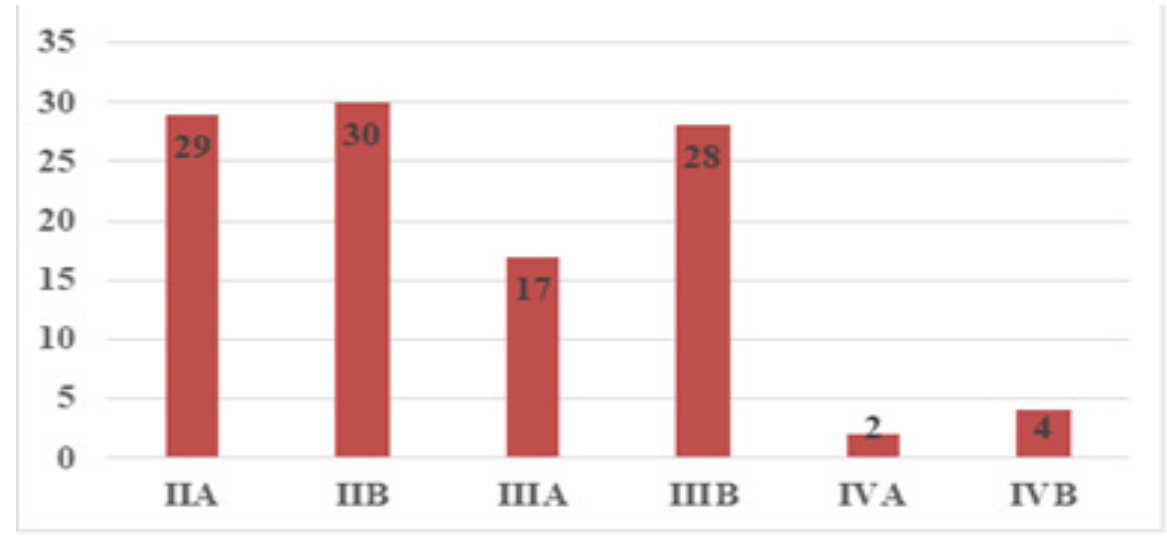

Figure 3. The Distribution of Cancer Stages 
is the type that most frequently infects cervical tissue with a prevalence almost the same as HPV-18 (70-80\%). This virus can infect cervical tissue with infecting one genotype or several genotypes at once (Senapati et al., 2017).

The L1 of HPV-16 and HPV-18 is mostly used in developing prolactive vaccines to suppress HPV infections, which have been widely implemented in various countries. This is based on the ability of the L1 gene to reproduce itself like the virus; however, it does not have the viral genome to infect and instead elicits an immune response. Previous studies in Morocco have found that the diversity of HPV-16 is very high and illustrates phylogenic to the regions of Europe (E), Africa (Af), and North America (NA-1). However, there are no studies that provide information on L1 variants in Morocco and its effect on the effectiveness of existing vaccines. Genomic analysis of the L1 HPV-16 sequence in the sample showed changes from 17 nucleotides including missense mutations A / C (6694), G / A (6801), G / A (6819), ATG insertion (6903), and GAT deletions (6950). In general, 12 sillent mutations were found from various studies in India, the Netherlands, and Brazil. The interesting thing is that all samples analyzed are different from the reference sequence with the insertion of the ATC codon at position 6903 and the deletion of GAT at position 6951 (El-Aliani et al., 2017).

Based on the analysis of the 26 isolates sample sequence compared to reference K02718.1, mutations were found along the $1596 \mathrm{bp}$ sequence tested. This causes molecular variations, which occur in the form of SNPs (Single Nucleotide Polymorphism) in all isolates of the sample in the form of C / G (6240), A / G (6432), T / G (6686), C / T (6823), C / T (6823) substrate sequences occured along the length of the sample isolates observed. This can cause changes in amino acids and the insertion of nucleotide bases ACT (6901) followed by GAT base deletions (6953) and T deletions (5786) (Table 2).

Research by Hirose et al., (2018). Reported changes in certain nucleotide sequences, which indicate substitution of $\mathrm{C}$ to $\mathrm{T}$ mostly produces missense mutations. However, it does not affect the nature of the virus. Persistent infection with high-risk HPV is associated with precancerous growth in cervical cancer that is common in India. This is due to the fact that there are variations in HPV type 16 in HPV genes in certain geographical regions, which causes different oncogenic functions and potentials (Griffiths et al., 2015).

Researches in India have also reported an insertion in 6901 by ATC seen at the genome level, resulting in insertion at 448 in amino acids that produces serine. This change has been also seen in all GAT removal / deletion samples which occurres at 6590 genome level and causes removal at 465 aspartate amino acids. This was seen in $100 \%$ of the samples. These insertions and deletions have not been reported in previous studies (Pillai et al., 2009).

Among all the mutations that occurred along the isolate sample sequence, it was found that the most common insertion was the insertion of the ATC base of all the isolate samples.Deletions of GAT nucleotide bases in all isolatesamples was also observed. Substitution between the purine base and other purines or the purine base with other pyrimidine bases also occurred in all $100 \%$ isolate samples. In Gurgel et al., 2015, the occurrence of ATC insertion and GAT deletions led to a change in amino acids in 447-threonine / 448-serine and 445-aspartate in all samples. Mutations that occur in these isolates are misense mutations which mean changes that occur in nucleotides also change the amino acids produced. Changes to the HPV-16 L1 nucleotide gene can influence capsid structure, introduction of the immune system, and neutralization of the virus (Gurgel et al., 2015).

In this study, phylogenetic tree analysis showed that HPV 16 sample isolate in Riau Indonesia had a kinship with Asia America (AA). In contrast to the results of this study, Fadhilah et al., 2015 showed that the isolates of cervical cancer patients in Bandung Indonesia were in a subgroup with HPV from Asia and East Asia. However, the isolate kinship is far from the cluster of African, Thailand , and Asian American ( Fadhilah et al., 2015). Studies based on phylogenetic analysis show that HPV type 16 is most commonly found in line with European lineages (Kabekkodu et al., 2015).

In summary, there are molecular variations in isolates of HPV type 16 samples from combined samples in the microbiology laboratory of Universitas Riau, Pekanbaru, namely the insertion of ACT (6901) and Deletion (6953) C / G substitution (6240), A / G (6432) C / T (6823) ) found in all isolate samples, and T/ G (6686) in the isolate samples of HPV06, HPV17 and HPV179, which can alter the amino acids produced.

\section{Author Contribution Statement}

The Authors confirm contribution to the paper as follows: study conception and design : Maya Savira and Andani Eka Putra; data collection: Maya Savira; analysis and intepretation of result: Maya Savira, Donel S, Andani Eka Putra; author draft manuscript preparation: Maya Savira and Donel S; all authors are reviewed the result and approved the final version of the manuscript: Maya Savira, Donel S, Andani Eka Putra, Yusrawati, Nur Indrawati Lipoeto.

\section{Acknowledgements}

None.

Statement conflict of Interest

No.

\section{References}

Bray F, Ferlay J, Soerjomataram I, et al (2018). Global cancer statistics 2018: GLOBOCAN estimates of incidence and mortality worldwide for 36 cancers in 185 countries. $C A$ Cancer J Clin, 68, 394-424.

Bruni L, Barrionuevo-Rosas L, Serrano B, et al (2017). Human papillomavirus and Related Diseases Report in Indonesia. In 'Cervical cancer incidence in Indonesia'. ICO Inf Cent HPV Cancer. Institute Català d'Oncologia, Barcelona, pp 6-32.

Choi Y, Park J (2016). Clinical Significance of Human Papillomavirus Genotyping. J Gynecol Oncol, 27, 21.

Costa S, Venturoli S, Origoni M, et al (2015). Performance Asian Pacific Journal of Cancer Prevention, Vol $23 \quad 91$ 
of HPV DNA testing in the follow-up after treatment of high-grade cervical lesions, adenocarcinoma in situ (AIS) and microinvasive carcinoma. Ecancermedicalscience, 9, $1-7$.

El-Aliani A, Alaoui MA El, Chaoui I, et al (2017). Naturally occurring capsid protein variants $\mathrm{L} 1$ of human papillomavirus genotype 16 in Morocco. Bioinformation, 13, 241-8.

Fadhilah FR, Sahiratmadja EK, Safitri R, Maskoen AM, Susanto H (2015). Analisis Filogenetik Gen L1 Human Papillomavirus 16 pada Penderita Kanker Serviks di Bandung. $M K B, 47,174-8$.

Faraji F, Zaidi M, Fakhry C, Gaykalova DA (2017). Molecular mechanisms of human papillomavirus-related carcinogenesis in head and neck cancer. Microbes Infect, 19, 464-75.

Ferlay J, Soerjomataram I, Dikshit R, et al (2015). Cancer incidence and mortality worldwide: Sources, methods and major patterns in GLOBOCAN 2012. Int J Cancer, 136, 359-86.

Griffiths AJF, Wessler SR, Caroll SB, Doebley J (2015). Introduction to genetic analysis. Eds Eleventh. In 'Population Genetic'. W.H. Freeman \& Company, United States of America, pp 671-96.

Gurgel APAD, Chagas BS, do Amaral CM, et al (205). Prevalence of Human Papillomavirus Variants and Genetic Diversity in the L1 Gene and Long Control Region of HPV16, HPV31, and HPV58 Found in North-East Brazil. Biomed Res Int, 2015, 1-12.

Hirose Y, Onuki M, Tenjimbayashi Y, et al (2018). Within-Host Variations of Human Papillomavirus Reveal APOBEC Signature Mutagenesis in the Viral Genome. $J$ Virol, 92, $1-38$.

Jing Y, Wang T, Chen Z, et al (2018). Phylogeny and polymorphism in the long control regions E6, E7, and L1 of HPV Type 56 in women from southwest China. Mol Med Rep, 17, 7131-41.

Kabekkodu SP, Bhat S, Pandey D, et al (2015). Prevalence of human papillomavirus types and phylogenetic analysis of HPV-16 L1 variants from Southern India. Asian Pac J Cancer Prev, 16, 2073-80.

Kessler TA (2017). Cervical Cancer: Prevention and Early Detection. Semin Oncol Nurs, 33, 172-83.

Kovacevic G, Milosevic V, Knezevic P, et al (2019). Prevalence of oncogenic Human papillomavirus and genetic diversity in the L1 gene of HPV16 HPV18 HPV31 and HPV33 found in women from Vojvodina Province Serbia. Biologicals, $\mathbf{5 8}, 57-63$.

Kumar N (2016). Cervical Cancer; a Nightmare for Womanhood: Review of Recent Advances. Womens Health Gynecol, 2, $1-9$.

Mendes D, Bains I, Vanni T, Jit M (2015). Systematic review of model-based cervical screening evaluations. BMC Cancer, $15,1-11$.

Pan J, Kavanagh K, Cuschieri K, et al (2019). Increased risk of HPV-associated genital cancers in men and women as a consequence of pre-invasive disease. Int J Cancer, 145, 427-34.

Pangribowo S (2019). Beban Kanker di Indonesia. In Jenis Kanker Terbanyak'. Pusat Data dan Informasi Kementerian Kesehatan RI, Indonesia, pp 8-9.

Pillai MR, Hariharan R, Babu JM, et al (2009). Molecular variants of HPV-16 associated with cervical cancer in Indian population. Int J Cancer, 125, 91-103.

Rezai M, Saravani R, Sargazi S, et al (2019). Achillea Wilhelmsii C. KochHydroalcoholic Extract Induces Apoptosis and Alters LIN28B and p53 Gene Expression in Hela Cervical Cancer Cells. Reports Biochem Mol Biol, 8, 318-25.

Schellenbacher C, Roden RBS, Kirnbauer R (2017).
Developments in L2-based human papillomavirus (HPV) vaccines. Virus Res, 231, 166-75.

Senapati R, Nayak B, Kar SK, Dwibedi B (2017). HPV genotypes co-infections associated with cervical carcinoma: Special focus on phylogenetically related and non-vaccine targeted genotypes. PLoS One, 12, 1-10.

Téllez L, Michelli E, Mendoza JA, et al (2015). Persistent infection with high-risk human papilloma viruses: Cohort study, Mérida, Venezuela. Ecancermedicalscience, 9, 1-17.

Zouheir Y, Daouam S, Hamdi S, Alaoui A, Fechtali T (2016). Knowledge of human papillomavirus and acceptability to vaccinate in adolescents and young adults of the Moroccan Population. J Pediatr Adolesc Gynecol, 29, 292-8.

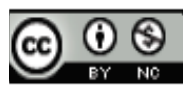

This work is licensed under a Creative Commons AttributionNon Commercial 4.0 International License. 